Case report

\title{
Recurrent appendicitis following successful conservative management of an appendicular mass in association with a foreign body: a case report
} Sudeshna Sar ${ }^{1}$, Kamal K Mahawar ${ }^{1}$, Ralph Marsh $^{2}$ and Peter K Small ${ }^{1}$

\author{
Addresses: ${ }^{1}$ Department of General Surgery, Sunderland Royal Hospital, Kayll Road, Sunderland SR4 7TP, UK \\ ${ }^{2}$ Department of Radiology, Sunderland Royal Hospital, Kayll Road, Sunderland SR4 7TP, UK \\ Email: SS - sondra.sara2005@gmail.com; KKM* - kamal_mahawar@hotmail.com; RM - ralph.marsh@chs.northy.nhs.uk; \\ PKS - peter.small@chs.northy.nhs.uk \\ * Corresponding author
}

Received: 26 May 2009 Accepted: 24 June 2009 Published: 24 July 2009

Cases Journal 2009, 2:7776 doi: 10.4076/1757-1626-2-7776

This article is available from: http://casesjournal.com/casesjournal/article/view/7776

(c) 2009 Sar et al; licensee Cases Network Ltd.

This is an Open Access article distributed under the terms of the Creative Commons Attribution License (http://creativecommons.org/licenses/by/3.0),

which permits unrestricted use, distribution, and reproduction in any medium, provided the original work is properly cited.

\begin{abstract}
Introduction: Interval appendicectomy is not routinely indicated after successful resolution of an appendix mass. Whether this policy can also be applied to patients with appendicular foreign body presenting with an appendix mass remains a matter of debate. We report here a patient who presented with recurrent symptoms following conservative management of an appendicular mass associated with a foreign body in the appendix. We also review the available literature briefly.

Case presentation: A 70 year old gentleman was admitted with right iliac fossa pain, tenderness, and raised inflammatory markers. A computed tomography scan of his abdomen showed an appendix mass with a small abscess and a linear opaque foreign body. His symptoms resolved completely on conservative management with intravenous antibiotics. A colonoscopy few weeks later was unremarkable. He presented with recurrent symptoms a few months later. A repeat computed tomography scan showed persistent appendicular abscess with the same foreign body in it. A laparotomy with appendicectomy, abscess drainage and removal of the foreign body was carried out with satisfactory outcome.

Conclusion: Surgeons should be aware of appendicular foreign body as a cause of persistent/ recurrent symptoms after conservative management of appendicular mass. These patients require prompt surgery and formal appendicectomy. Interval appendicectomy should be considered.
\end{abstract}

\section{Case presentation}

A 70 year old, white, British male patient was admitted as an emergency with right iliac fossa pain, tenderness, and raised inflammatory markers. A computed tomography scan of his abdomen showed an appendix mass with a small abscess and a linear opaque foreign body in it (Figure 1). His symptoms subsided completely on conservative management with intravenous antibiotics. Colonoscopy two months later did not show anything untoward. At a follow up review in surgical clinic, 


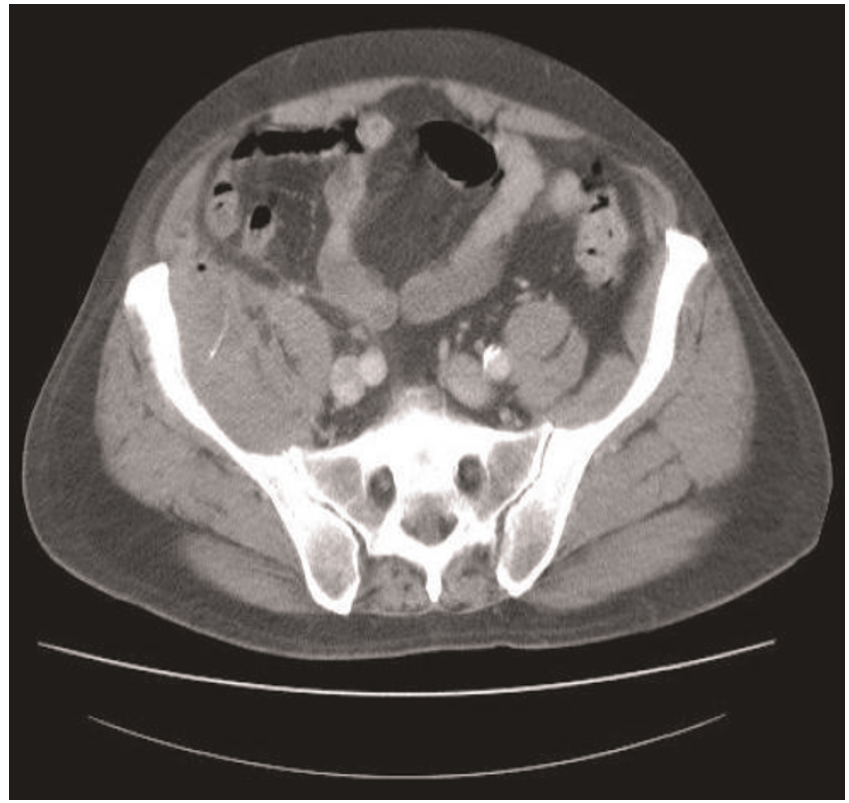

Figure I. CT scan of the abdomen showing an appendix mass with a small abscess and a linear opaque foreign body.

appendicectomy was not deemed necessary and the patient was discharged from further follow up.

The patient presented again to us a few months later with recurrent symptoms in the right iliac fossa and raised inflammatory markers. A repeat computed tomography scan of the abdomen showed a persistent abscess in the area with the same foreign body which had migrated into the iliopsoas muscle (Figure 2). The patient underwent appendicectomy, drainage of abscess and removal of the foreign body (Figure 3). He made a satisfactory postoperative recovery and was well at the time of his clinic appointment 3 months after the surgery.

\section{Discussion}

Foreign bodies are a rare cause for appendicitis [1,2]. The first case was recorded in the $18^{\text {th }}$ century when in 1736 , Claudius Amyand, surgeon in the Westminster Hospital, London operated on an 11 year old boy who had a persistent faecal fistula in the right scrotal hernia. During surgery the appendix was found to be perforated by a pin [3]. In 1971, Balch and Silver reported on 7 foreign bodies in the appendix after reviewing approx 13228 cases of appendicectomies [4]. A review of 71,000 appendicectomies by Collins showed that $51.8 \%$ contained a foreign body, of which only 5.5\% were unusual foreign bodies. The rest were parasitic worms or faecoliths $[5,6]$.

Risk factors include sharp, thin, stiff, long objects and objects weighting greater than the bowel fluid content thus

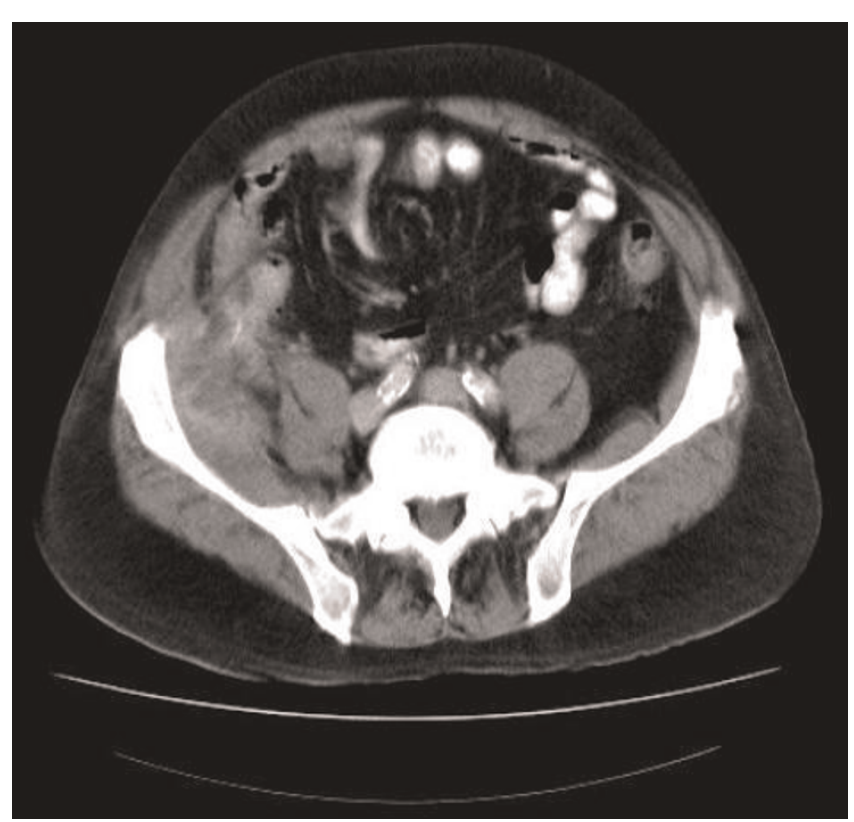

Figure 2. Repeat CT scan of the abdomen a few months later showing the same foreign body embedded in iliopsoas muscle with an abscess in the area.

enabling them to arrest in the caecum and gravitate towards its dependent position [4,7]. A variety of foreign bodies have been found in the appendix ranging from sewing needles, retained shot pellets, tongue studs,

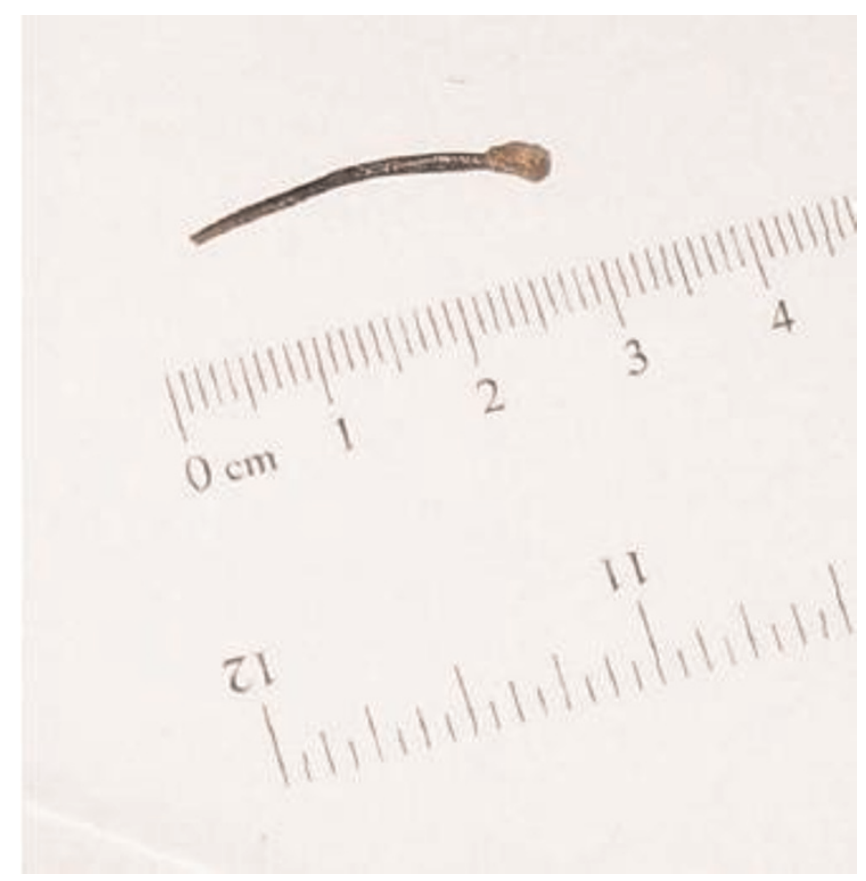

Figure 3. The foreign body removed from the abscess cavity at the time of surgery. 
endodontic files, drill bits, dog hair, toothbrush bristle, toothpicks, fishing lines, mercury (after ingestion of the bulb of a thermometer) and condom fragments [4,6,8-12]. Complications usually depend on the size and shape of the object. Elongated, sharp objects which account for $75 \%$ of foreign bodies in the appendix are more likely to cause perforations, appendicular abscesses and peritonitis. Blunt objects, which account for $<12 \%$ of all the foreign bodies can become coated with faecal coating, enlarge and fully or partially obstruct the appendicular lumen, resulting in appendicular mucocoele or decubital perforation $[4,5,10,13]$.

Presentation can vary from asymptomatic to abdominal pain, with or without vomiting or diarrhoea. A history of recent ingestion of the foreign body is sometimes obtained. On examination low grade pyrexia is often seen with associated tenderness/peritonism in the right iliac fossa or lower abdomen. White cell counts and C reactive protein may be raised depending upon the degree of inflammation. Radio opaque foreign bodies are readily visualised in the right lower quadrant. Free intraperitoneal air is seen if the object has caused perforation of the gastrointestinal tract. A computed tomography scan would usually be required to confirm the diagnosis.

A symptomatic appendicular foreign body will need an appendicectomy. Most patients present with features of appendicitis and undergo an appendicectomy. However in some high risk patients with diagnostic difficulties or those presenting with appendix mass, a non operative approach may be adopted initially. After successful non operative management of appendicitis, interval appendicectomy is not routinely necessary and can safely be omitted [14]. As far as we are aware there is no available study in the published English medical literature evaluating this approach in patients with appendicular foreign body presenting with an appendix mass. In our patient the initial non operative approach had to be abandoned in favour of surgery.

\section{Conclusion}

Surgeons should be aware of appendicular foreign body as a cause of appendicitis/appendix mass. This can present as a cause of persistent/recurrent symptoms after conservative management of appendicular mass. These patients require prompt surgery and formal appendicectomy. Whether these patients should undergo routine interval appendicectomy remains to be investigated.

\section{Consent}

Written informed consent was obtained from the patient for publication of this case report and accompanying images. A copy of the written consent is available for review from the journal's Editor-in-Chief.

\section{Competing interests}

The authors declare that they have no competing interests.

\section{Authors' contributions}

SS co-ordinated the entire effort and wrote the manuscript. KKM conceived the idea, helped with the draft of the case report, and obtained consent from the patient. RM interpreted the radiological scans and contributed the images. PKS was the consultant surgeon in charge of the patient, who also performed his surgery. He also supervised the entire effort. All authors read and approved the final manuscript.

\section{References}

I. Barnes FS: Foreign bodies as an etiological factor in appendicitis. Texas State J Med 1907, 3:263-266.

2. Fowler RH: Foreign body appendicitis. Ann Surg 1912, 56:427-436.

3. Creese PG: The first appendectomy. Surg Gynaecol Obstet 1953, 97:643-652.

4. Balch CM, Silver D, Durham NC: Foreign bodies in the appendix: report of eight cases and review of the literature. Arch Surg 1971, 102:14-20.

5. Collins DC: A study of 50,000 specimens of the human vermiform appendix. Surg Gynaecol Obstet 1955, 101:437-445.

6. Collins DC: Seventy one thousand human appendix specimens. Am J Proctol 1963, 14:265-28I.

7. Klingler PJ, Seelig MH, DeVault KR, Wetscher GJ, Floch NR, Branton SA, Hinder R: Ingested foreign bodies within the appendix: A 100 year review of the literature. Dig Dis 1998, I6:308-3|4.

8. Miller GG, Fraser GC, Jevon G: "Pilonidal appendicitis" or "the hair of the dog": an unusual case of foreign body. J Pediatr Surg 1996, 31:703.

9. Hadi HIA, Quah HM, Maw A: A missing tongue stud: An unusual Appendicular foreign body. Int Surg 2006, 91:87-89.

10. Conti F, Gentilli S, Mauri A: Foreign body decubitus: unusual cause of acute appendicitis. Minerva Chir 1993, 48:713-716.

II. Renner K, Holzer B, Hochwater G, Weihsbeck E, Scheissel R: Needle perforation of the appendix. Dig Surg 2000, I7:4|3-4I4.

12. Thomsen LC, Appleton SS, Engstrom HI: Appendicitis induced by an endodontic file. Gen Dent 1989, 37:50-51.

13. Klinlger PJ, Smith SL, Abendstein BJ, Brenner E, Hinder RA: Management of ingested foreign bodies within the appendix: a case report with review of the literature. Am J Gastroenterol 1997, 92:2235-2298.

14. Deakin DE, Ahmed I: Interval appendicectomy after resolution of adult inflammatory appendix mass - is it necessary? Surgeon 2007, 5:45-50. 